\title{
Decline in calcitonin receptor expression in osteocytes with age
}

\author{
Jonathan H Gooi ${ }^{*}{ }^{+}$, Ling Yeong Chia ${ }^{*}$, Nicole C Walsh, Morten A Karsdal', \\ Julian M W Quinn ${ }^{\ddagger}$, T John Martin and Natalie A Sims
}

St Vincent's Institute, and Department of Medicine, at St Vincent's Hospital, The University of Melbourne, 9 Princes Street, Fitzroy, Victoria 3065, Australia ${ }^{1}$ Nordic Bioscience, Inc., Copenhagen, Denmark

*(J H Gooi and LY Chia contributed equally to this work)

'J H Gooi is now at Department of Medicine, NorthWest Academic Centre, The University of Melbourne, Sunshine Hospital, St Albans, Victoria, Australia

${ }^{\ddagger} J$ M W Quinn is now at Prince Henry's Institute, Clayton, Victoria 3168, Australia

\author{
Correspondence \\ should be addressed \\ to N A Sims \\ Email \\ nsims@svi.edu.au
}

\begin{abstract}
We have previously shown that co-administration of the transient osteoclast inhibitor, salmon calcitonin (sCT), blunts the anabolic effect of parathyroid hormone (PTH) in young rats and increases osteocytic expression of the bone formation inhibitor sclerostin (Sost). To determine whether this also occurs in adult animals, we co-administered SCT with PTH to 6-month-old sham-operated (SHAM) and ovariectomised (OVX) rats. While SCT reduced the stimulatory effect of PTH on serum amino-terminal propeptide of type 1 procollagen levels, in contrast to its influence in young rats, $\mathrm{SCT}$ did not reduce the anabolic effect of PTH on femoral bone mineral density, tibial trabecular bone volume or bone formation rate in 6-month-old SHAM or OVX rats. Quantitative real-time PCR analysis of femoral metaphyses collected 1 and $4 \mathrm{~h}$ after a single PTH injection confirmed a significant increase in mRNA levels for interleukin $6(/ / 6)$ and ephrinB2 (EfnB2), and a significant reduction in Sost and dentin matrix protein-1 (Dmp1) in response to PTH. However, in contrast to observations in young rats, these effects were not modified by co-administration of $\mathrm{sCT}$, nor did $\mathrm{sCT}$ significantly modify Sost, Dmp1, or matrix extracellular phosphoglycoprotein (Mepe) mRNA levels. Furthermore, while CT receptor (CTR) mRNA (Calcr) was readily detected in GFP+ osteocytes isolated from young (3-week-old) DMP1-GFP mice, Calcr levels in osteocytes declined as mice aged, reaching levels that were undetectable in long bone at 49 weeks of age. These data indicate that osteocyte-mediated responses to CT are most likely to be of physiological relevance in young rodents.
\end{abstract}

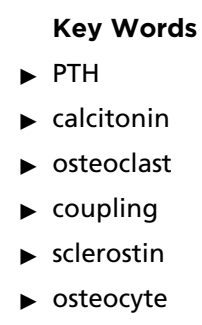

Journal of Endocrinology (2014) 221, 181-191

\section{Introduction}

The maintenance of bone structure throughout life occurs by the process of bone remodelling, which consists of co-ordinated actions of bone-forming osteoblasts and bone-resorbing osteoclasts within a remodelling space, known as the basic multicellular unit (BMU). In adult animals, the amount of bone removed by osteoclasts in each BMU is matched by the bone-forming activity of osteoblasts, suggesting the existence of 'coupling' signals between these two cell types (Frost 1964). The mechanisms by which coupling occurs may include release of growth factors such as transforming growth factor $\beta$ and insulin-like growth factors from the bone matrix, or the production of secreted factors by active osteoclasts (Karsdal et al. 2008, Henriksen et al. 2012), 
such as cardiotrophin-1 (Walker et al. 2008), semaphorin 4D (Negishi-Koga et al. 2011), and sphingosine-1-phosphate (Pederson et al. 2008), or by contact-dependent mechanisms that could include ephrinB2 (EfnB2; Zhao et al. 2006) or semaphorin 3A (Hayashi et al. 2012); reviewed in Henriksen et al. (2014).

When the rate of bone remodelling is increased, as occurs with injections of parathyroid hormone (PTH), any coupling signals from the osteoclast that stimulate osteoblasts should also be increased. This led us to hypothesise that osteoclast-derived coupling factors may be involved in the anabolic action of PTH (Martin \& Sims 2005). Consistent with this, in postmenopausal women treated with a combination of PTH and alendronate (a bisphosphonate therapy that blocks osteoclast action), PTH anabolic effect was reduced with alendronate treatment (Black et al. 2003). Later work in mouse models indicated that mice lacking osteoclasts did not respond fully to anabolic PTH therapy (Demiralp et al. 2002). Both of these earlier publications reflect the effects of a continuous blockade or absence of osteoclasts. Although salmon calcitonin (sCT) is not in common use as a therapy, it provides a useful method to rapidly and transiently inhibit osteoclast activation to determine whether this is required for PTH anabolic action. Indeed, we found that co-administration of sCT blocked the PTH anabolic response in normal young female rats (Gooi et al. 2010). In addition to any coupling-mediated actions, we found that SCT treatment also increased the expression of sclerostin (Gooi et al. 2010), an inhibitor of bone formation that is secreted by osteocytes. This stimulation of sclerostin by sCT is likely to be mediated by CT receptors (CTRs) that we, and others, identified in bone matrixembedded osteocytes (Paic et al. 2009, Gooi et al. 2010). PTH anabolic action suppresses sclerostin production (Bellido et al. 2005, Leupin et al. 2007) and PTH anabolic action is limited in mice that overexpress sclerostin (Kramer et al. 2010). Thus, sCT could impair the anabolic action of PTH through two independent mechanisms, or their combination: by blocking osteoclast activation (thereby reducing osteoclast-derived coupling factors) and stimulating sclerostin expression.

While SCT administration clearly reduced PTH actions on bone in our earlier study (Gooi et al. 2010), this was carried out in young (3-week-old) rats with a high level of bone turnover, and hormonal and other features that do not reflect those of adult patients with osteoporosis, who would most commonly be treated with PTH anabolic therapy (Teriparatide). To explore further the influence of transient osteoclast inhibition and sclerostin stimulation, we tested the effects of combined treatment of sCT and PTH in 6-month-old sham-operated (SHAM) and ovariectomised (OVX) rats.

\section{Materials and methods}

\section{Animal experiments}

Female Sprague-Dawley rats were purchased from the Animal Resources Centre (Canning Vale, Australia). Dentin matrix protein-1 (DMP1)-green fluorescent protein (GFP) mice, that express GFP under the control of $8 \mathrm{~kb}$ of the Dmp1 promoter region and $4439 \mathrm{bp}$ of the first exon, first intron and part of the second exon, to restrict GFP expression to osteocytes (Kalajzic et al. 2004), were obtained from the colony of Dr Hong Zhou, ANZAC Research Institute (Sydney). The animals were housed in a $12 \mathrm{~h}$ light: $12 \mathrm{~h}$ darkness cycle with food and water provided ad libitum. All animal experiments were approved by the St Vincent's Health Animal Ethics Committee.

To determine whether sCT administration modifies the anabolic response to PTH(1-34), 5-month-old female Sprague-Dawley rats $(284 \pm 2.9 \mathrm{~g})$ were either SHAM operated or OVX and allowed to undergo bone loss for 4 weeks. This experiment was carried out 6 months after our earlier study using the same peptide preparations (Gooi et al. 2010). Synthetic human PTH(1-34) was purchased from Bachem (Bubendorf, Switzerland). Synthetic salmon CT was the kind gift of Dr M Azria, Novartis AG. The rats were randomly allocated to control (vehicle), PTH, sCT, or PTH + sCT treatment groups with seven rats per group. The rats were given daily s.c. injections, 5 days a week for 3 weeks, of either vehicle $(0.9 \%$ saline with $2 \%$ heatinactivated rat serum), $30 \mu \mathrm{g} / \mathrm{kg} \mathrm{PTH}(1-34), 0.3 \mu \mathrm{g} / \mathrm{kg} \mathrm{sCT}$, or a combination of PTH $(1-34)$ and $\mathrm{sCT}(\mathrm{PTH}+\mathrm{sCT})$ at the same doses. The PTH dose of $30 \mu \mathrm{g} / \mathrm{kg}$ was based on previous experiments in similar aged animals (McManus et al. 2008). We used this dose to achieve an anabolic effect that could be measured with confidence, but was less than the maximal anabolic dose. The dose of $0.3 \mu \mathrm{g} / \mathrm{kg}$ sCT was based on an in vivo bioassay to determine the minimal dose to obtain a transient decrease in serum calcium in both young and adult OVX rats (Gooi et al. 2010). The rats were weighed daily and doses were adjusted weekly according to weight changes over the 4-week period. Three hours after the last injection, a terminal blood sample was collected by cardiac puncture exsanguination. Tibiae were collected for histomorphometric analysis and femoral samples for analysis of densitometric and

Published by Bioscientifica Ltd 
geometric parameters by peripheral quantitative computed tomography.

To determine the acute effects of each treatment on serum biochemistry and gene expression in bone, 5 -month-old female Sprague-Dawley rats (254 $\pm 5 \mathrm{~g}$ ) were OVX. Four weeks later, the rats were randomly divided into eight groups of seven and treated after overnight fast with a single s.c. injection of vehicle, hPTH(1-34), sCT, or a combination of both hPTH(1-34) and sCT as above. Terminal blood samples were collected by cardiac puncture exsanguination under inhalation anaesthesia at 1 or $4 \mathrm{~h}$ after injection. The femoral distal epiphysis including the growth plate was removed, cleaned of muscle and ligament attachments and a subjacent $5 \mathrm{~mm}$ band of the metaphyseal primary spongiosa, including marrow, was resected and snap-frozen in liquid nitrogen for RNA preparation as previously described (Onyia et al. 1995).

\section{Biochemical analyses}

Serum calcium was measured by reaction with $o$-cresolphthalein (Sigma-Aldrich). Serum levels of C-telopeptide fragments of collagen type I (CTX-1) were measured using the RatLaps ELISA (Nordic Bioscience, Inc., Copenhagen, Denmark), CTX-2 levels were measured using the Serum Pre-Clinical Cartilaps ELISA (Nordic Bioscience, Inc.) and amino-terminal propeptide of type 1 procollagen (P1NP) was assayed by mass spectrometry (Han et al. 2007). Serum PTH in rats was measured by a rat Intact PTH ELISA Kit (Immunotopics, San Clemente, CA, USA), which does not detect the human PTH(1-34) peptide used for injections.

\section{Histomorphometry and pQCT}

Tibiae collected after treatment for 3 weeks were dehydrated in acetone and embedded in methylmethacrylate (Sims et al. 2006). Undecalcified $5 \mu \mathrm{m}$ longitudinal sections were stained with toluidine blue for histomorphometry of the secondary spongiosa of the proximal tibial metaphysis as previously described (Sims et al. 2004). The region measured was a $1 \mathrm{~mm}$ long $\times 1.4 \mathrm{~mm}$ wide rectangle commencing $1.9 \mathrm{~mm}$ below the growth plate to avoid the primary spongiosa, subcortical bone, and trabecular bone newly formed during the 4-week treatment period. Femoral densitometric and geometric parameters were measured by pQCT (Stratec X-CT Research SA+, version 5.5; Pforzheim, Germany) as previously described (Sims et al. 2006). Briefly, metaphyseal scans of the distal femur were taken at a resolution of
$70 \mu \mathrm{m}$. Trabecular and cortical measurements (including circumference) were taken at a distance proximal to the distal growth plate of 5 and $25 \%$ of the length of the femur, respectively; trabecular bone mineral density (Tb.BMD) was determined as the inner $45 \%$ of the total area (peel mode 20). Interassay coefficients of variation were $<1 \%$.

\section{RNA isolation from rat femora}

RNA was prepared from the individual samples collected after the acute treatment study using a QIAGEN RNeasy Lipid Midi Kit after homogenisation in QIAzol Lysis Reagent (Qiagen) with an LS-10-35 Polytron homogeniser (Brinkmann Instruments, Westbury, NY, USA) (Gooi et al. 2010).

\section{Osteocyte isolation}

Calvariae and long bones (femora and tibiae) were removed from 3-, 10-, 27-32- and 49-week-old DMP1-GFP transgenic mice (Kalajzic et al. 2004). After removal, long bones were flushed and cut into $1-2 \mathrm{~cm}$ pieces, then both calvariae and long bones were subjected to seven sequential 15 min digestions in a $2 \mathrm{ml}$ mixture containing $4 \mathrm{mg}$ dispase (Gibco) and 2 mg collagenase type 2 (Worthington, Lakewood, NJ, USA). Previous use of this method, but using only four digests, provided GFP + cells that expressed abundant levels of sclerostin (Gooi et al. 2010), which, in bone, is expressed only by matrix-embedded osteocytes. Cell fractions one to seven were collected, pooled and resuspended in $\alpha$-modified Eagle's medium (Gibco) containing 10\% FBS and centrifuged. Cells were resuspended, filtered, and sorted for GFP on a FACS Aria (BD Biosciences) as previously described (Gooi et al. 2010). $100 \%$ GFP + cells were used for cDNA preparations; this population made up an average of $1.63 \%$ of the sorted calvarial cells (range was $<0.1-2.7 \%$ ) and $0.45 \%$ of the sorted long-bone cells (range was $<0.1-1.2$ ). To confirm GFP positivity, a separate preparation of GFP cells was examined on an Olympus IX-81 live cell imager.

\section{CDNA preparation and PCR}

cDNA was prepared from RNA using random hexamers (Promega) and Superscript III (Invitrogen) according to the manufacturer's protocol. Real-time quantitative RT-PCR was carried out using SYBR Green detection on a Stratagene Mx3000P (Invitrogen) as previously described (Gooi et al. 2010). Cycling conditions were $\left(95^{\circ} \mathrm{C}\right.$ for $\left.10^{\prime}\right)$

Published by Bioscientifica Ltd 
and $\left(95^{\circ} \mathrm{C}\right.$ for $15^{\prime \prime}$ and $60^{\circ} \mathrm{C}$ for $\left.1^{\prime}\right) \times 40$ cycles, followed by dissociation step $\left(95^{\circ} \mathrm{C}\right.$ for $1^{\prime}, 55^{\circ} \mathrm{C}$ for $30^{\prime \prime}$, and $95^{\circ} \mathrm{C}$ for $\left.30^{\prime \prime}\right)$. The samples were analysed using MxPro Software (Agilent Technologies, Santa Clara, CA, USA) and reported using linear $\Delta C \mathrm{t}$ values normalised to hypoxanthine phosphoribosyltransferase 1 (Hprt1). The expression of this housekeeping gene did not differ between experimental groups. Primers for genes of interest are all previously published (Gooi et al. 2010, Walker et al. 2010). Expression of the two Calcr gene transcripts Calcr1a and Calcr $1 b$ was determined by RT-PCR using primers designed to distinguish the two transcripts based on amplification product size (Calcr1a, 446 and Calcr1b, 557 ) when run on a $2 \%$ TBE agarose gel (Gooi et al. 2010). Quantitative real-time PCR was carried out as mentioned earlier. Calcr was amplified using the following primers: forward, $5^{\prime}$-AGC CAC AGC CTA TCA GCA CT- $3^{\prime}$ and reverse, 5'-GAC CCA CAA GAG CCA GGT AA-3'. Since Hprt1 levels were highly variable in cell preparations, a second housekeeping gene, BMS1 homolog (Bms1), a stable and ubiquitously expressed ribosome assembly protein (Karbstein 2007), was used for the isolated cells using the following primer set: forward, 5'-AGA AGT CTA CCC GGG CGC CA-3' and reverse, 5'-ACC GGC CCA GGT TGT GAA TCT CT- $3^{\prime}$.

\section{Statistical analyses}

All data presented are mean \pm s.E.M. Statistically significant differences were determined by one-way or two-way ANOVA followed (where significant) by Fisher's protected least significant difference post hoc test. $P<0.05$ was considered significant. Statistical analyses were carried out using StatView 5.0.1 (SAS Institute, Cary, NC, USA).

\section{Results}

In 6-month-old rats, transient inhibition of osteoclasts by co-administration of SCT with PTH did not attenuate the anabolic action of PTH in either SHAM or OVX rats. pQCT of femoral samples detected no significant effect of the low doses of PTH and SCT used in this study on 6-month-old SHAM rats (Fig. 1A). OVX rats showed a significant $(\sim 55 \%)$ reduction in Tb.BMD compared with SHAM rats. PTH significantly increased Tb.BMD in OVX rats, while sCT treatment did not significantly alter it. In contrast to our previous observations in young rats (Gooi et al. 2010), co-administration of sCT with PTH did not modify the anabolic effect of PTH on Tb.BMD (Fig. 1A).
This result was confirmed by histomorphometry at a second site, the tibia. Here, as expected, trabecular bone volume (BV/TV) and trabecular thickness (Tb.Th) were significantly reduced after ovariectomy (Fig. 1B and C). In the OVX rat, daily administration of $30 \mu \mathrm{g} / \mathrm{kg}$ of hPTH(1-34) significantly increased BV/TV and Tb.Th, restoring BV/TV to the levels observed in SHAM animals, and increasing $\mathrm{Tb}$.Th to values significantly greater than SHAM while reducing trabecular separation (Tb.Sp; Fig. 1D). The effect of PTH was less in the SHAM rats, where no increase in BV/TV or Tb.Sp was observed, but there was a significant increase in $\mathrm{Tb}$.Th, indicating a mild anabolic effect (Fig. 1C and D). Administration of $0.3 \mu \mathrm{g} / \mathrm{kg}$ sCT daily for 4 weeks to SHAM or OVX animals did not significantly modify BV/TV, Tb.Th, Tb.Sp, or trabecular number (Tb.N) in either SHAM or OVX rats (Fig. 1B, C, D, E and F). Co-administration of sCT with PTH did not alter the anabolic response of PTH in either SHAM or OVX rats (Fig. 1B, C, D, E and F).

Dynamic histomorphometric analysis showed that PTH treatment in both SHAM and OVX rats substantially increased bone formation rate (Fig. 2A), regardless of whether PTH was co-administered with sCT. The increased bone formation rate related mainly to an increase in mineralising surface (Fig. 2B), but mineral appositional rate was also increased in OVX rats treated with PTH (Fig. 2C).

Serum biochemical analysis confirmed inhibition of osteoclast activity by the dose of CT used in this study (Table 1). CT treatment with or without PTH co-treatment resulted in significantly reduced levels of serum CTX-1 in both SHAM and OVX animals, indicating successful inhibition of osteoclast activity. Type 2 collagen is the major component of articular cartilage, and its degradation is used as a marker of cartilage breakdown, particularly in osteoarthritis and rheumatoid arthritis (Christgau et al. 2001, Dam et al. 2009). Administration of sCT significantly reduced CTX-2 levels in both SHAM and OVX animals $3 \mathrm{~h}$ after the final injection. This effect was greater in OVX animals, indicating that sCT may have protective effects on cartilage degradation, consistent with previous reports (Behets et al. 2004, Bagger et al. 2005, Sondergaard et al. 2012). Administration of PTH in SHAM animals did not significantly alter CTX-2 levels, whereas in OVX animals PTH treatment significantly decreased CTX-2 levels. This data support recent work indicating that administration of PTH has some protective effects on cartilage degradation (Kudo et al. 2011). This may in part be due to direct effects of PTH/PTHrP in stimulating cartilage formation, as observed at the growth plate

Published by Bioscientifica Ltd. 

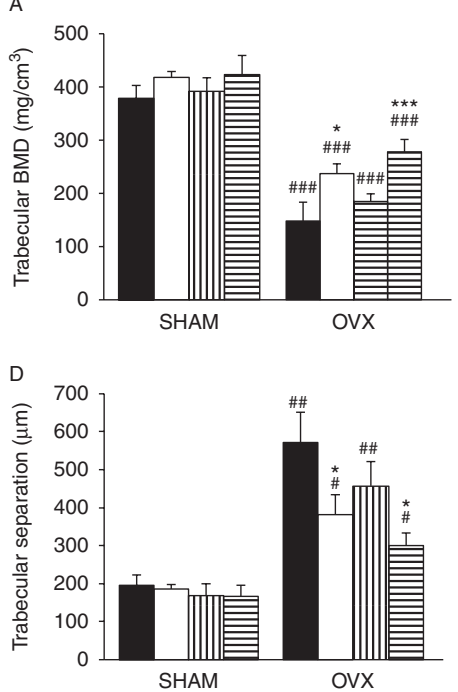

B

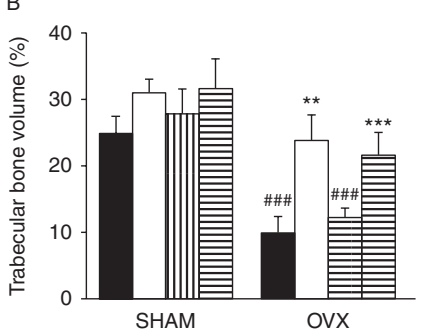

E

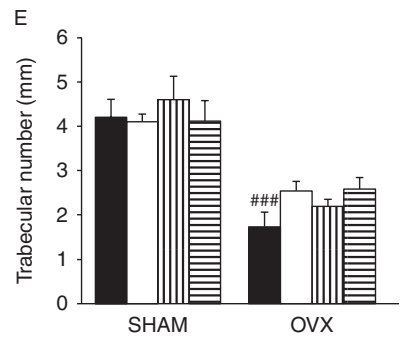

C

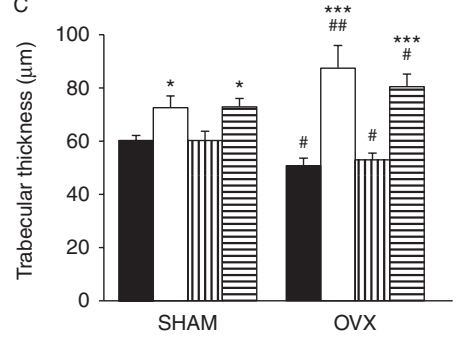

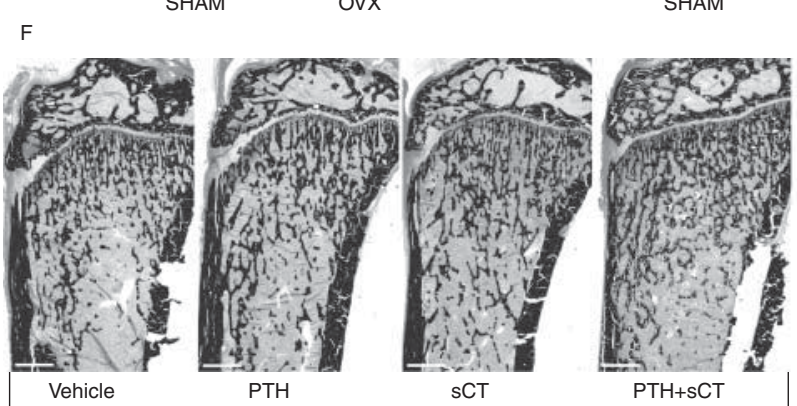

SHAM

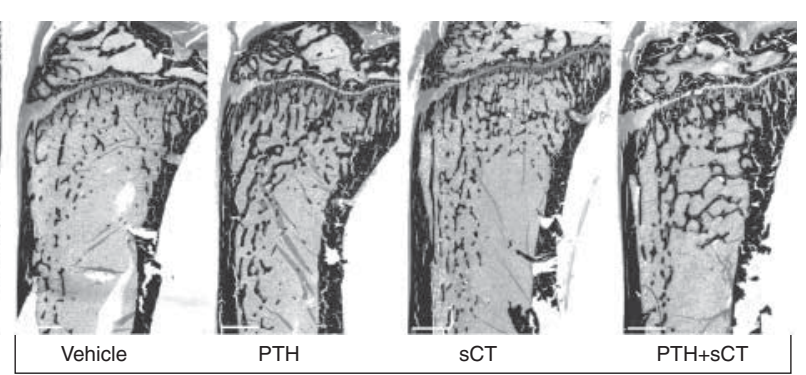

OVX

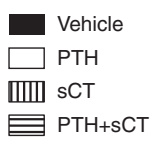

$\mathrm{PTH}+\mathrm{SCT}$
Figure 1

Effects of salmon calcitonin (sCT) and parathyroid hormone (PTH) on bone mass in sham (SHAM) and ovariectomised (OVX) 6-month-old SpragueDawley rats characterised by PQCT of femora (A) and histomorphometric analysis of tibial sections (B, C, D, E and F). (A) Femoral trabecular BMD (Tb.BMD), (B) tibial trabecular bone volume (BV/TV), (C) trabecular thickness (Tb.Th), (D) trabecular separation (Tb.Sp), and (E) trabecular number (Tb.N). (F) Representative von Kossa stained tibial sections for each treatment group. Scale bar $=1 \mathrm{~mm}$. Data are mean \pm s.E.M. ( $n=7$ per group). $* P<0.05, * * P<0.01$, and $* * * P<0.001$ compared with vehicle-treated animals in the same surgery group. ${ }^{\#} P<0.05,{ }^{\# \#} P<0.01$, and ${ }^{\# \# \#} P<0.001$ compared with vehicle-treated sham animals.

mediated resorption (Gundberg \& Weinstein 1986, Ivaska et al. 2004) inhibited by sCT. Consistent with this, serum osteocalcin levels with combined PTH $+\mathrm{sCT}$ treatment were similar to the levels in vehicle-treated animals.

In our previous study of young rats treated with PTH and SCT, we noted that SCT significantly increased Sost mRNA levels, an effect that may have attenuated the anabolic response to PTH (Gooi et al. 2010). To determine whether this also occurs in adult OVX rats, we analysed mRNA levels of Sost and other key genes that were regulated by PTH and sCT in that study. As previously observed (Greenfield et al. 1993, Allan et al. 2008), administration of a single dose of $30 \mu \mathrm{g} / \mathrm{kg} \mathrm{hPTH}(1-34)$ increased interleukin 6 (Il6) and EfnB2 mRNA levels dramatically at $1 \mathrm{~h}$ after injection (Fig. $3 \mathrm{~A}$ and B). http://joe.endocrinology-journals.org DOI: 10.1530/JOE-13-0524
(๑) 2014 Society for Endocrinology Printed in Great Britain 

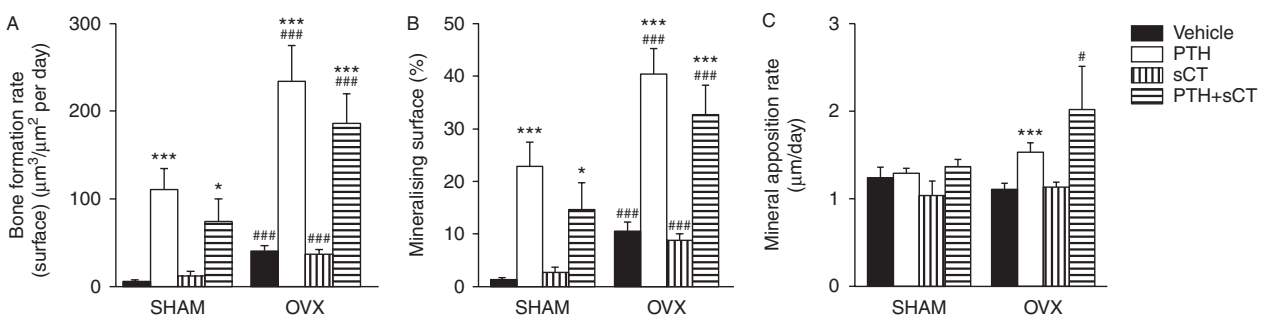

\section{Figure 2}

Effects of salmon calcitonin (sCT) and parathyroid hormone (PTH) on bone formation in sham (SHAM) and ovariectomised (OVX) 6-month-old Sprague-Dawley rats. Histomorphometric analysis of bone formation parameters: (A) bone formation rate, (B) mineralising surface,

Although PTH significantly reduced Sost mRNA levels at $4 \mathrm{~h}$ post-injection, sCT treatment did not influence the expression of this gene (Fig. 3C). Two other osteocytic genes, Dmp1 and matrix extracellular phosphoprotein (Mepe), were downregulated by sCT administration in young rats (Gooi et al. 2010). In this study, while Dmp1 mRNA levels were significantly reduced by PTH at $4 \mathrm{~h}$ post injection (Fig. 3D), there were no significant changes in Dmp1 or Mepe mRNA levels in response to sCT (Fig. 3E).

Since there was no effect of sCT treatment on osteocyte marker genes in the older rats, we sought to identify the expression of Calcr in osteocytes in older rodents. Since digests of bone specimens would contain both osteoclasts, which contain very high numbers of CTR, as well as osteocytes, we FACS-isolated osteocytes from the DMP1GFP mouse line that expresses the GFP reporter specifically in osteocytes (Kalajzic et al. 2004). Our previous observation that the $\mathrm{C} 1 \mathrm{a}$ isoform of the CTR transcript is expressed in the osteocytes isolated from calvariae of C57BL/6 neonatal mice (Gooi et al. 2010) was confirmed in this more highly purified population extracted from and (C) mineral apposition rate. Data are mean \pm S.E.M. ( $n=7$ per group). $* P<0.05$, and $* * * P<0.001$ compared with vehicle-treated animals. ${ }^{\#} P<0.05$, and ${ }^{\# \# \#} P<0.001$ compared with vehicle-treated sham animals.

immature 3-week-old male and female mice (Fig. 4A). Calcr mRNA was also detected in osteocytes isolated from long bones from these mice (Fig. 4A). However, when samples were collected from male and female 49-week-old mice, while Calcr mRNA was again detected in the osteocytes from calvarial bone it was not possible to detect Calcr mRNA in the isolated osteocytes from the long bones of these older mice (Fig. 4B).

To further investigate changes in Calcr expression in osteocytes with age, real-time PCR was carried out on these samples and on GFP + osteocytes isolated from calvariae and long bones from 10-, 27- and 32-week-old DMP1-GFP mice (Fig. 4C and D). Calcr levels were greater in calvarial osteocytes compared with long-bone osteocytes, particularly in females. While Calcr mRNA was readily detected in osteocytes from both sites in samples from 3-week-old mice (Ct of 28-30), all other ages showed a lower level of Calcr at both sites in both sexes, which reached the lower limit of detection at 49 weeks ( $\mathrm{Ct}$ of $>38$ ). Consistent with the semi-quantitative PCR result, Calcr levels reached the lower limit of detection in long-bone osteocytes from 49 -week-old male and female mice.

Table 1 Effects of sCT and PTH on serum biochemistry. Data are mean \pm s.E.M. ( $n=7$ per group)

\begin{tabular}{|c|c|c|c|c|}
\hline & CTX-1 (ng/ml) & CTX-2 (ng/ml) & P1NP (nM) & Osteocalcin (ng/ml) \\
\hline \multicolumn{5}{|l|}{ SHAM } \\
\hline Vehicle & $14.4 \pm 1.1$ & $13.6 \pm 3.5$ & $6.9 \pm 0.7$ & $108.3 \pm 11.6$ \\
\hline PTH & $15.7 \pm 1.2$ & $8.2 \pm 1.9$ & $10.7 \pm 0.8^{\dagger}$ & $229.0 \pm 17.1^{\ddagger}$ \\
\hline $\mathrm{sCT}$ & $11.1 \pm 0.7 *$ & $2.7 \pm 2.5^{*}$ & $6.5 \pm 0.6$ & $57.1 \pm 8.7^{\dagger}$ \\
\hline $\mathrm{PTH}+\mathrm{sCT}$ & $11.4 \pm 0.9 *$ & $0.6 \pm 0.6^{\dagger}$ & $8.2 \pm 0.5$ & $120.6 \pm 8.1$ \\
\hline \multicolumn{5}{|l|}{ oVX } \\
\hline Vehicle & $18.8 \pm 1.2^{\S}$ & $18.4 \pm 1.7$ & $9.5 \pm 0.8^{\S}$ & $188.4 \pm 21.0^{\S}$ \\
\hline PTH & $15.7 \pm 1.2$ & $8.4 \pm 3.2 *$ & $14.0 \pm 0.8^{\dagger}$ & $336.0 \pm 10.9^{\ddagger}$ \\
\hline $\mathrm{sCT}$ & $13.2 \pm 0.6^{\ddagger}$ & $0.7 \pm 0.4^{\ddagger}$ & $9.0 \pm 0.6$ & $67.3 \pm 14.3^{\ddagger}$ \\
\hline $\mathrm{PTH}+\mathrm{sCT}$ & $10.6 \pm 1.2^{\ddagger}$ & $0.3 \pm 0.2^{\ddagger}$ & $11.5 \pm 0.6$ & $193.8 \pm 13.4$ \\
\hline
\end{tabular}

CTX-1, serum levels of C-terminal cross-linking telopeptide of type 1 collagen; P1NP, amino-terminal propeptide of type 1 procollagen; osteocalcin measured $3 \mathrm{~h}$ following last injection of a 3-week treatment protocol of PTH $(30 \mu \mathrm{g} / \mathrm{kg}), \mathrm{sCT}(0.3 \mu \mathrm{g} / \mathrm{kg})$, or PTH + sCT co-administration in 6-month-old sham and ovariectomised Sprague-Dawley rats. ${ }^{*} P<0.05,{ }^{\dagger} P<0.01,{ }^{\ddagger} P<0.001$ vs vehicle-treated animals with the same surgery. ${ }^{\S} P<0.05$ vs vehicle-treated SHAM.

http://joe.endocrinology-journals.org DOI: 10.1530/JOE-13-0524
C 2014 Society for Endocrinology Printed in Great Britain
Published by Bioscientifica Ltd. 

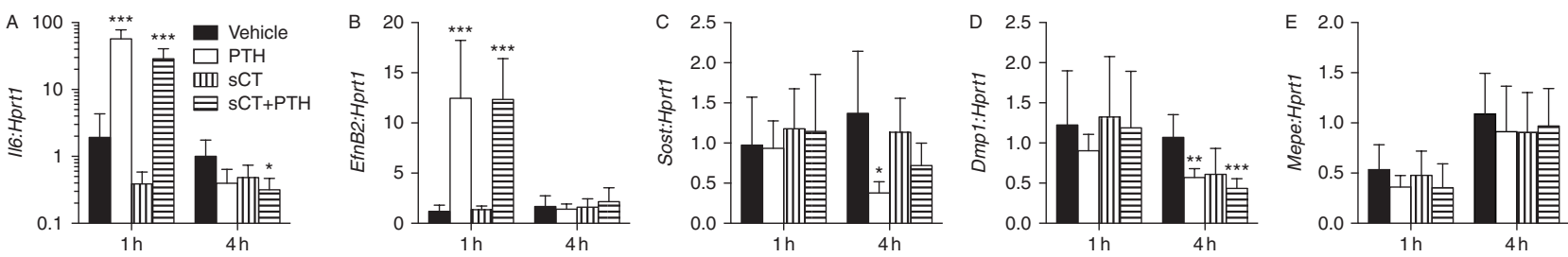

Figure 3

Real-time PCR analysis of genes regulated by PTH and CT in 6-month-old Sprague-Dawley rats, 1 month after ovariectomy. (A) $1 / 6$, (B) EfnB2, (C) Sost, (D) Dmp1, and (E) Mepe as determined by qPCR of metaphyseal specimens collected 1 and $4 \mathrm{~h}$ after a single injection of vehicle (black), $30 \mu \mathrm{g} / \mathrm{kg}$ PTH

\section{Discussion}

This study demonstrates that a dose of sCT that is sufficient to suppress osteoclast activity does not significantly attenuate the anabolic effect of PTH in 6-monthold SHAM and OVX rats. This contrasts with our previous observations in young (3-week-old) rats where the effect of PTH on trabecular bone mass was greatly inhibited by a low dose of sCT that both transiently inhibited osteoclasts and increased sclerostin mRNA levels (Gooi et al. 2010). In both experiments, the proportional reduction in CTX-1 levels was similar (30\%). The lack of effect of sCT on PTH action in the older rats may be explained by an age-related reduction in CTR transcription observed in osteocytes of mice between weanling age ( 3 weeks) and all later time points. This may explain the reduction in the influence of sCT on sclerostin between weanling (3-week-old) and adult (6-month-old) rats.

Since osteoclast inhibition by sCT treatment was observed in both young and 6-month-old rats, the ability of sCT treatment to block the anabolic action of PTH only in the young rats may relate to an altered response of osteocytes to sCT. Although these two experiments were not carried out side-by-side, our previous observations in young rats that PTH increased Il6 and EfnB2 expression and reduced sclerostin were confirmed in this study in adult rats, as observed in other models (Greenfield et al. 1993, Keller \& Kneissel 2005, Allan et al. 2008). However, the effects of sCT on osteocytic Sost, Mepe, and Dmp1 mRNA levels were strikingly different; while 3-week-old rats treated with sCT displayed increased levels of Sost mRNA, and decreased Mepe and Dmp1 levels (Gooi et al. 2010), there was no effect of sCT administration on any osteocytic genes in 6-month-old OVX rats. This may be explained by lower osteocytic Calcr expression in the long bones with age. Since it was not possible to study this directly in adult rat bone, due to the difficulties of separating osteocytes from osteoclasts, that express (white), $0.3 \mu \mathrm{g} / \mathrm{kg} \mathrm{sCT} \mathrm{(vertical} \mathrm{stripes),} \mathrm{or} \mathrm{both} \mathrm{PTH} \mathrm{and} \mathrm{SCT} \mathrm{(horizontal}$ stripes). Data are mean levels of the genes of interest relative to Hprt1 \pm s.E.M. ( $n=7$ per group). ${ }^{*} P<0.05, * * P<0.01$, and $* * * P<0.001$ compared with vehicle-treated specimens at the same time point.

dramatically higher levels of CTR (Gooi et al. 2010), we used DMP1-GFP mice (Kalajzic et al. 2004), which allowed purification of osteocytes by sorting for GFP expression. In these cells, isolated from male and female mice, we observed readily detectable Calcr, but osteocytes from older animals expressed Calcr levels that decreased with increasing age.

Our previous work identifying CTR expression in osteocytes made use of calvarial bone specimens in young mice (Gooi et al. 2010), and the same is true of the work of Paic et al. (2009) that described Calcr in isolated osteocytes. Our current work suggests that CTR expression by osteocytes is not constant, but is reduced as rodents age, most dramatically in the long bones. Agedependent downregulation of CTR isoforms has been reported previously in the kidney, where CTR expression is high during renal development but is strongly reduced between postnatal days 10 and 30 (Tikellis et al. 2003).

Since young CTR and CT/calcitonin gene-related peptide (CGRP)-deficient mice have been reported to exhibit increased bone formation (Hoff et al. 2002, Dacquin et al. 2004), and sCT treatment stimulates levels of sclerostin, a bone formation inhibitor, in both calvariae and long bones of young mice (Gooi et al. 2010), we can conclude that CT inhibits bone formation in young mice, and that this may be mediated by effects on osteocytes. Age-related downregulation of Calcr in long bones may provide some explanation for age-related phenotypic changes previously reported in the CT/CGRP-deficient mice. Although a high level of bone formation was observed at 1 and 3 months of age (Hoff et al. 2002), the phenotype is dominated by increased resorption and cortical porosity in the long bones at 12 months of age (Huebner et al. 2006), presumably due to the lack of CT inhibitory action on osteoclasts. Furthermore, in the long bones, the action of endogenous CT to increase sclerostin in a state of high bone turnover (i.e. in the young animal)

Published by Bioscientifica Ltd. 


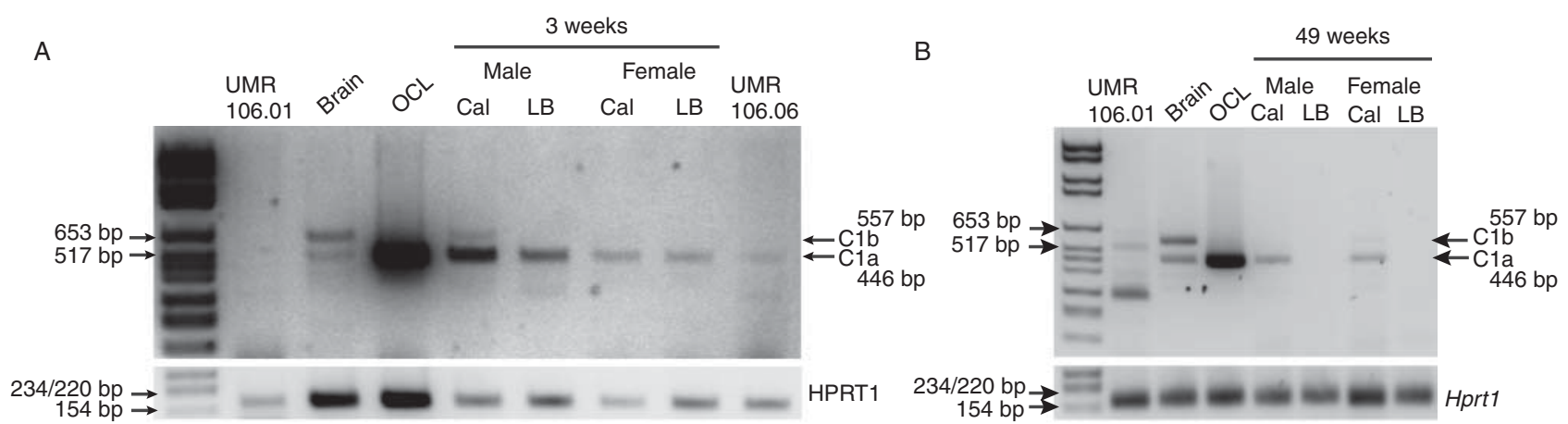

C

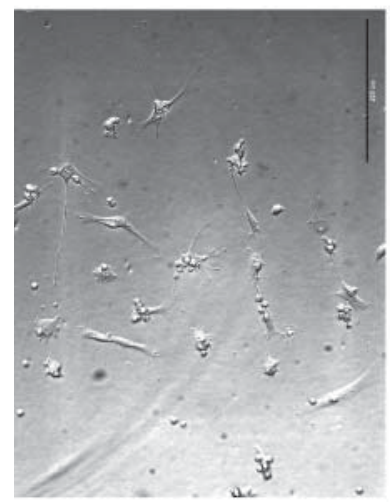

Phase contrast

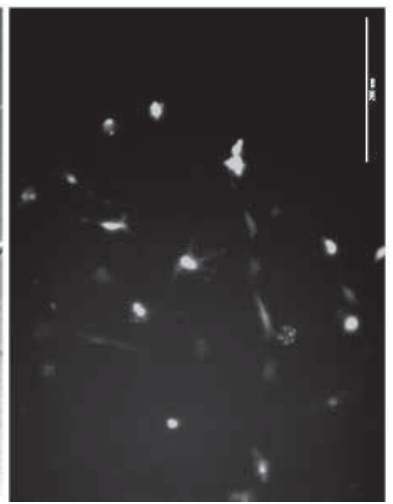

FITC
D
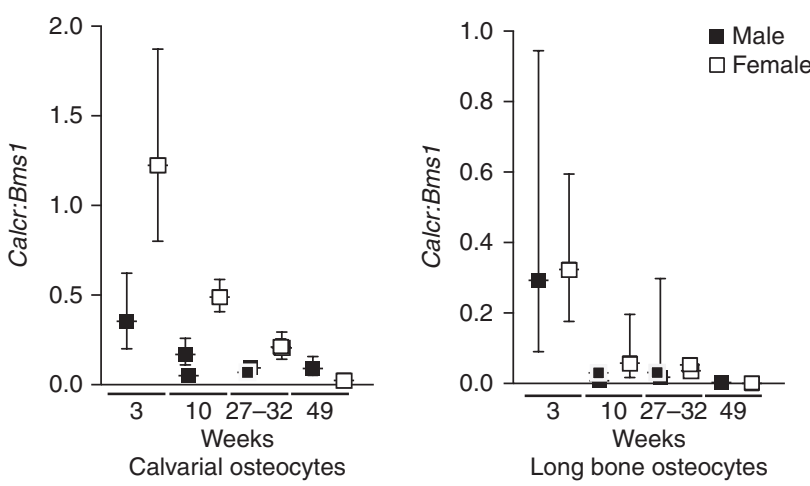

expression, relative to that of housekeeping gene Bms1 in GFP+ osteocytes, isolated by FACS from DMP1-GFP mouse Cal and LB. To obtain sufficient cells, osteocytes were isolated from bones of two to four mice, and pooled as follows: 3 weeks, three to four mice; 10 weeks, two pooled samples, each from two mice; 27-32 weeks of age, two pooled samples, each from two to three mice; and 49 weeks, two mice. Error bars denote the range of relative expression levels. Full colour version of this figure available via http://dx.doi.org/10.1530/JOE-13-0524.

experiment; a longer-term study might reveal whether there is a slight attenuation of structural effects. Since sCT did not influence osteocytic gene expression in this study, this very mild attenuation may be due to the transient inhibition of osteoclast activity by sCT, and subsequent transient blockade of osteoclast-derived coupling factors.

The participation of osteoclast-derived coupling factors in the anabolic action of PTH may be greater in states of high bone remodelling, as exists in the young animal compared with the adult (Friedl et al. 2007, McManus et al. 2008). Notably, other experimental work using mouse models that have indicated a role for active osteoclasts in anabolic action of PTH also focused on young mice (Demiralp et al. 2002, Koh et al. 2005). It is also possible that while transient inhibition of osteoclasts is sufficient to block PTH anabolic action in young animals, http://joe.endocrinology-journals.org DOI: $10.1530 / J O E-13-0524$
(C) 2014 Society for Endocrinology Printed in Great Britain 
any osteoclastic contribution to PTH-induced bone formation in older animals may be prevented only by a constant blockade of osteoclast activity. This is what would have been achieved with alendronate treatment in postmenopausal women (Black et al. 2003, Finkelstein et al. 2010). Recent data from postmenopausal women have indicated that the combination of PTH (Teriparatide) with each of two more potent osteoclast inhibitors, the bisphosphonate zoledronic acid (Cosman et al. 2011) and anti-RANKL antibody (Denosumab) (Tsai et al. 2013), yielded biochemical marker data indicating that PTHanabolic action was maintained. This might be through an action of PTH on osteoblast lineage cells in the existing BMUs as well as promotion of bone formation at modelling sites. The mechanism by which transient inhibition is capable of reducing PTH-induced bone formation in young rats may relate to the greater number of active bone remodelling units and greater areas of bone modelling present at this age.

Co-administration of sCT with hPTH(1-34) has been reported previously in adult and aged OVX rats; however, the main focus of these earlier works was quite different, to explore whether PTH anabolic action could be enhanced by combining it with osteoclast inhibition (Mosekilde et al. 1994, Li et al. 1995, DeLuca \& Dani 2001, Washimi et al. 2007). In each of those studies, high doses of sCT (ten- to 30-fold higher than the current study) were used with the aim of increasing bone mass by suppressing osteoclast activity. The key effects observed in the first, and most detailed of these studies (Mosekilde et al. 1994), was a more rapid increase in bone mass with combination therapy that was not sustained; long-term combination therapy did not differ from the result of PTH treatment alone, indicating that PTH anabolic action is not limited by osteoclast inactivation. In one study, the effects of PTH on mineralising surface were inhibited, indicating that the combination of the two treatments resulted in an antiresorptive effect overall, rather than enhanced anabolism (Washimi et al. 2007). In contrast to those studies, the very low dose of CT used in the current study was deliberately chosen to be insufficient to prevent or reverse ovariectomy-induced bone loss, but chosen to transiently inhibit osteoclast activity at the time of PTH administration. The sCT dose we used did significantly inhibit both bone and cartilage resorption, as shown by serum CTX-1 and CTX-2 levels, and significantly reduced bone turnover, as indicated by serum osteocalcin levels. Any effects, therefore, that this dose of sCT might exert on inhibiting osteoclast activity would still occur, providing further evidence that the inhibition of PTH anabolic effects observed in the young mice related specifically to the effect of sCT on the osteocyte.

This study indicates that the previously described mechanism in which sCT treatment induces osteocytic sclerostin production in the young animal (Gooi et al. 2010) may reflect a regulatory mechanism that is only applicable in young animals, where CTR is expressed at high levels by osteocytes. We suggest that the effects of endogenous CT or injected SCT on sclerostin may not be observed in the older animal model due to an age-related reduction in osteocytic CTR expression. The high level of CTR expression in osteocytes from young rodents may reflect a developmental role of CTR that limits bone formation, but does not persist through maturity.

\section{Declaration of interest}

M A K own stocks in Nordic Bioscience, Inc. All other authors have no conflicts of interest that could be perceived as prejudicing the impartiality of the research reported.

\section{Funding}

The work was supported by NHMRC (Australia) Programme grant 345401 and project grant number 1002730 to N A S, T J M, and J M W Q and by the Victorian State Government Operational Infrastructure Support Program; J H G was supported by an Osteoporosis Australia scholarship; and N A S was supported by a NHMRC (Australia) Senior Research Fellowship.

\section{Acknowledgements}

The authors acknowledge the help of Prof. John Wark and the late Mrs Susan Kantor at the Department of Medicine, Royal Melbourne Hospital, University of Melbourne for the use of their PQCT and thank Dr Bomie Han at Eli Lilly Laboratories for serum P1NP analysis, Ingrid Poulton for histology assistance, and the staff at the Bioresources Centre, St Vincent's Health Melbourne for excellent animal care.

\section{References}

Allan EH, Hausler KD, Wei T, Gooi JH, Quinn JM, Crimeen-Irwin B, Pompolo S, Sims NA, Gillespie MT, Onyia JE et al. 2008 EphrinB2 regulation by PTH and PTHrP revealed by molecular profiling in differentiating osteoblasts. Journal of Bone and Mineral Research 23 1170-1181. (doi:10.1359/jbmr.080324)

Bagger YZ, Tanko LB, Alexandersen P, Karsdal MA, Olson M, Mindeholm L, Azria M \& Christiansen C 2005 Oral salmon calcitonin induced suppression of urinary collagen type II degradation in postmenopausal women: a new potential treatment of osteoarthritis. Bone 37 425-430. (doi:10.1016/j.bone.2005.04.032)

Behets C, Williams JM, Chappard D, Devogelaer JP \& Manicourt DH 2004 Effects of calcitonin on subchondral trabecular bone changes and on osteoarthritic cartilage lesions after acute anterior cruciate ligament deficiency. Journal of Bone and Mineral Research 19 1821-1826. (doi:10.1359/JBMR.040609)

Bellido T, Ali AA, Gubrij I, Plotkin LI, Fu Q, O’Brien CA, Manolagas SC \& Jilka RL 2005 Chronic elevation of parathyroid hormone in mice

Published by Bioscientifica Ltd. 
reduces expression of sclerostin by osteocytes: a novel mechanism for hormonal control of osteoblastogenesis. Endocrinology 146 4577-4583. (doi:10.1210/en.2005-0239)

Black DM, Greenspan SL, Ensrud KE, Palermo L, McGowan JA, Lang TF, Garnero P, Bouxsein ML, Bilezikian JP \& Rosen CJ 2003 The effects of parathyroid hormone and alendronate alone or in combination in postmenopausal osteoporosis. New England Journal of Medicine 349 1207-1215. (doi:10.1056/NEJMoa031975)

Christgau S, Garnero P, Fledelius C, Moniz C, Ensig M, Gineyts E, Rosenquist C \& Qvist P 2001 Collagen type II C-telopeptide fragments as an index of cartilage degradation. Bone 29 209-215. (doi:10.1016/ S8756-3282(01)00504-X)

Cosman F, Eriksen EF, Recknor C, Miller PD, Guanabens N, Kasperk C, Papanastasiou P, Readie A, Rao H, Gasser JA et al. 2011 Effects of intravenous zoledronic acid plus subcutaneous teriparatide [rhPTH (1-34)] in postmenopausal osteoporosis. Journal of Bone and Mineral Research 26 503-511. (doi:10.1002/jbmr.238)

Dacquin R, Davey RA, Laplace C, Levasseur R, Morris HA, Goldring SR, Gebre-Medhin S, Galson DL, Zajac JD \& Karsenty G 2004 Amylin inhibits bone resorption while the calcitonin receptor controls bone formation in vivo. Journal of Cell Biology 164 509-514. (doi:10.1083/ jcb.200312135)

Dam EB, Loog M, Christiansen C, Byrjalsen I, Folkesson J, Nielsen M, Qazi AA, Pettersen PC, Garnero P \& Karsdal MA 2009 Identification of progressors in osteoarthritis by combining biochemical and MRI-based markers. Arthritis Research \& Therapy 11 R115. (doi:10.1186/ar2774)

Dani BA \& DeLuca PP 2001 Skeletal effects of parathyroid hormone (1-34) in ovariectomized rats with or without concurrent administration of salmon calcitonin. AAPS PharmSciTech 3 E27. (doi:10.1208/ps030427)

Demiralp B, Chen HL, Koh AJ, Keller ET \& McCauley LK 2002 Anabolic actions of parathyroid hormone during bone growth are dependent on c-fos. Endocrinology 143 4038-4047. (doi:10.1210/en.2002-220221)

Finkelstein JS, Wyland JJ, Lee H \& Neer RM 2010 Effects of teriparatide, alendronate, or both in women with postmenopausal osteoporosis. Journal of Clinical Endocrinology and Metabolism 95 1838-1845. (doi:10.1210/jc.2009-1703)

Friedl G, Turner RT, Evans GL \& Dobnig H 2007 Intermittent parathyroid hormone (PTH) treatment and age-dependent effects on rat cancellous bone and mineral metabolism. Journal of Orthopaedic Research $\mathbf{2 5}$ 1454-1464. (doi:10.1002/jor.20433)

Frost HM 1964 Dynamics of bone remodeling. In Bone Biodynamics, pp 315-333. Ed. HM Frost. Boston: Little, Brown \& Co.

Gooi JH, Pompolo S, Karsdal MA, Kulkarni NH, Kalajzic I, McAhren SH, Han B, Onyia JE, Ho PW, Gillespie MT et al. 2010 Calcitonin impairs the anabolic effect of PTH in young rats and stimulates expression of sclerostin by osteocytes. Bone 46 1486-1497. (doi:10.1016/j.bone.2010.02.018)

Greenfield EM, Gornik SA, Horowitz MC, Donahue HJ \& Shaw SM 1993 Regulation of cytokine expression in osteoblasts by parathyroid hormone: rapid stimulation of interleukin- 6 and leukemia inhibitory factor mRNA. Journal of Bone and Mineral Research 8 1163-1171. (doi:10.1002/jbmr.5650081003)

Gundberg CM \& Weinstein RS 1986 Multiple immunoreactive forms of osteocalcin in uremic serum. Journal of Clinical Investigation $\mathbf{7 7}$ 1762-1767. (doi:10.1172/JCI112499)

Han B, Copeland M, Geiser AG, Hale LV, Harvey A, Ma YL, Powers CS, Sato M, You J \& Hale JE 2007 Development of a highly sensitive, highthroughput, mass spectrometry-based assay for rat procollagen type-I $\mathrm{N}$-terminal propeptide (PINP) to measure bone formation activity. Journal of Proteome Research 6 4218-4229. (doi:10.1021/pr070288s)

Hayashi M, Nakashima T, Taniguchi M, Kodama T, Kumanogoh A \& Takayanagi H 2012 Osteoprotection by semaphorin 3A. Nature 485 69-74. (doi:10.1038/nature11000)

Henriksen K, Andreassen KV, Thudium CS, Gudmann KN, Moscatelli I, CrugerHansen CE, Schulz AS, Dziegiel MH, Richter J, Karsdal MA et al. 2012 A specific subtype of osteoclasts secretes factors inducing nodule formation by osteoblasts. Bone 51 353-361. (doi:10.1016/j.bone.2012.06.007)
Henriksen K, Karsdal M \& Martin TJ 2014 Osteoclast-derived coupling factors in bone remodeling. Calcified Tissue International 94 88-97. (doi:10.1007/s00223-013-9741-7)

Hoff AO, Catala-Lehnen P, Thomas PM, Priemel M, Rueger JM, Nasonkin I, Bradley A, Hughes MR, Ordonez N, Cote GJ et al. 2002 Increased bone mass is an unexpected phenotype associated with deletion of the calcitonin gene. Journal of Clinical Investigation 110 1849-1857. (doi:10. 1172/JCI200214218)

Huebner AK, Schinke T, Priemel M, Schilling S, Schilling AF, Emeson RB, Rueger JM \& Amling M 2006 Calcitonin deficiency in mice progressively results in high bone turnover. Journal of Bone and Mineral Research 21 1924-1934. (doi:10.1359/jbmr.060820)

Ivaska KK, Hentunen TA, Vaaraniemi J, Ylipahkala H, Pettersson K \& Vaananen HK 2004 Release of intact and fragmented osteocalcin molecules from bone matrix during bone resorption in vitro. Journal of Biological Chemistry 279 18361-18369. (doi:10.1074/jbc.M314324200)

Kalajzic I, Braut A, Guo D, Jiang X, Kronenberg MS, Mina M, Harris MA, Harris SE \& Rowe DW 2004 Dentin matrix protein 1 expression during osteoblastic differentiation, generation of an osteocyte GFP-transgene. Bone 35 74-82. (doi:10.1016/j.bone.2004.03.006)

Karbstein K 2007 Role of GTPases in ribosome assembly. Biopolymers $\mathbf{8 7}$ 1-11. (doi:10.1002/bip.20762)

Karsdal MA, Neutzsky-Wulff AV, Dziegiel MH, Christiansen C \& Henriksen K 2008 Osteoclasts secrete non-bone derived signals that induce bone formation. Biochemical and Biophysical Research Communications 366 483-488. (doi:10.1016/j.bbrc.2007.11.168)

Keller H \& Kneissel M 2005 SOST is a target gene for PTH in bone. Bone 37 148-158. (doi:10.1016/j.bone.2005.03.018)

Koh AJ, Demiralp B, Neiva KG, Hooten J, Nohutcu RM, Shim H, Datta NS, Taichman RS \& McCauley LK 2005 Cells of the osteoclast lineage as mediators of the anabolic actions of parathyroid hormone in bone. Endocrinology 146 4584-4596. (doi:10.1210/en.2005-0333)

Kramer I, Loots GG, Studer A, Keller H \& Kneissel M 2010 Parathyroid hormone (PTH) induced bone gain is blunted in SOST overexpressing and deficient mice. Journal of Bone and Mineral Research 25 178-189. (doi:10.1359/jbmr.090730)

Kudo S, Mizuta H, Takagi K \& Hiraki Y 2011 Cartilaginous repair of fullthickness articular cartilage defects is induced by the intermittent activation of PTH/PTHrP signaling. Osteoarthritis and Cartilage 19 886-894. (doi:10.1016/j.joca.2011.04.007)

Lanske B, Karaplis AC, Lee K, Luz A, Vortkamp A, Pirro A, Karperien M, Defize LH, Ho C, Mulligan RC et al. 1996 PTH/PTHrP receptor in early development and Indian hedgehog-regulated bone growth. Science $\mathbf{2 7 3}$ 663-666. (doi:10.1126/science.273.5275.663)

Leupin O, Kramer I, Collette NM, Loots GG, Natt F, Kneissel M \& Keller H 2007 Control of the SOST bone enhancer by PTH using MEF2 transcription factors. Journal of Bone and Mineral Research 22 1957-1967. (doi:10.1359/jbmr.070804)

Li M, Mosekilde L, Sogaard CH, Thomsen JS \& Wronski TJ 1995 Parathyroid hormone monotherapy and cotherapy with antiresorptive agents restore vertebral bone mass and strength in aged ovariectomized rats. Bone 16 629-635. (doi:10.1016/8756-3282(95)00115-T)

Martin TJ \& Sims NA 2005 Osteoclast-derived activity in the coupling of bone formation to resorption. Trends in Molecular Medicine 11 76-81. (doi:10.1016/j.molmed.2004.12.004)

McManus JF, Davey RA, Maclean HE, Doust EA, Chiu WS, Sims NA, Bouxsein ML, Glatt V, Zajac JD \& Danks JA 2008 Intermittent Fugu parathyroid hormone 1 (1-34) is an anabolic bone agent in young male rats and osteopenic ovariectomized rats. Bone 42 1164-1174. (doi:10.1016/j.bone.2008.01.015)

Mosekilde L, Danielsen CC \& Gasser J 1994 The effect on vertebral bone mass and strength of long term treatment with antiresorptive agents (estrogen and calcitonin), human parathyroid hormone-(1-38), and combination therapy, assessed in aged ovariectomized rats. Endocrinology 134 2126-2134. (doi:10.1210/endo.134.5.8156913) http://joe.endocrinology-journals.org DOI: 10.1530/JOE-13-0524
() 2014 Society for Endocrinology Printed in Great Britain 
Negishi-Koga T, Shinohara M, Komatsu N, Bito H, Kodama T, Friedel RH \& Takayanagi H 2011 Suppression of bone formation by osteoclastic expression of semaphorin 4D. Nature Medicine 17 1473-1480. (doi:10.1038/nm.2489)

Onyia JE, Bidwell J, Herring J, Hulman J \& Hock JM 1995 In vivo, human parathyroid hormone fragment (hPTH 1-34) transiently stimulates immediate early response gene expression, but not proliferation, in trabecular bone cells of young rats. Bone 17 479-484. (doi:10.1016/ 8756-3282(95)00332-2)

Paic F, Igwe JC, Nori R, Kronenberg MS, Franceschetti T, Harrington P, Kuo L, Shin DG, Rowe DW, Harris SE et al. 2009 Identification of differentially expressed genes between osteoblasts and osteocytes. Bone 45 682-692. (doi:10.1016/j.bone.2009.06.010)

Pederson L, Ruan M, Westendorf JJ, Khosla S \& Oursler MJ 2008 Regulation of bone formation by osteoclasts involves Wnt/BMP signaling and the chemokine sphingosine-1-phosphate. PNAS 105 20764-20769. (doi:10.1073/pnas.0805133106)

Robling AG, Bellido T \& Turner CH 2006 Mechanical stimulation in vivo reduces osteocyte expression of sclerostin. Journal of Musculoskeletal \& Neuronal Interactions 6354.

Sims NA, Jenkins BJ, Quinn JM, Nakamura A, Glatt M, Gillespie MT, Ernst M \& Martin TJ 2004 Glycoprotein 130 regulates bone turnover and bone size by distinct downstream signaling pathways. Journal of Clinical Investigation 113 379-389. (doi:10.1172/JCI19872)

Sims NA, Brennan K, Spaliviero J, Handelsman DJ \& Seibel MJ 2006 Perinatal testosterone surge is required for normal adult bone size but not for normal bone remodeling. American Journal of Physiology. Endocrinology and Metabolism 290 E456-E462. (doi:10.1152/ajpendo. 00311.2005)

Sondergaard BC, Catala-Lehnen P, Huebner AK, Bay-Jensen AC, Schinke T, Henriksen K, Schilling S, Haberland M, Nielsen RH, Amling M et al.
2012 Mice over-expressing salmon calcitonin have strongly attenuated osteoarthritic histopathological changes after destabilization of the medial meniscus. Osteoarthritis and Cartilage 20 136-143. (doi:10.1016/ j.joca.2011.11.004)

Tikellis C, Xuereb L, Casley D, Brasier G, Cooper ME \& Wookey PJ 2003 Calcitonin receptor isoforms expressed in the developing rat kidney. Kidney International 63 416-426. (doi:10.1046/j.1523-1755. 2003.00754.x)

Tsai JN, Uihlein AV, Lee H, Kumbhani R, Siwila-Sackman E, McKay EA, Burnett-Bowie SA, Neer RM \& Leder BZ 2013 Teriparatide and denosumab, alone or combined, in women with postmenopausal osteoporosis: the DATA study randomised trial. Lancet 382 50-56. (doi:10.1016/S0140-6736(13)60856-9)

Walker EC, McGregor NE, Poulton IJ, Pompolo S, Allan EH, Quinn JM, Gillespie MT, Martin TJ \& Sims NA 2008 Cardiotrophin-1 is an osteoclast-derived stimulus of bone formation required for normal bone remodeling. Journal of Bone and Mineral Research 23 2025-2032. (doi:10.1359/jbmr.080706)

Walker EC, McGregor NE, Poulton IJ, Solano M, Pompolo S, Fernandes TJ, Constable MJ, Nicholson GC, Zhang JG, Nicola NA et al. 2010 Oncostatin M promotes bone formation independently of resorption when signaling through leukemia inhibitory factor receptor in mice. Journal of Clinical Investigation 120 582-592. (doi:10.1172/JCI40568)

Washimi Y, Ito M, Morishima Y, Taguma K, Ojima Y, Uzawa T \& Hori M 2007 Effect of combined human PTH(1-34) and calcitonin treatment in ovariectomized rats. Bone $\mathbf{4 1}$ 786-793. (doi:10.1016/ j.bone.2007.06.019)

Zhao C, Irie N, Takada Y, Shimoda K, Miyamoto T, Nishiwaki T, Suda T \& Matsuo K 2006 Bidirectional ephrinB2-EphB4 signaling controls bone homeostasis. Cell Metabolism 4 111-121. (doi:10.1016/j.cmet. 2006.05.012)

Received in final form 4 February 2014

Accepted 10 February 2014

Accepted Preprint published online 10 February 2014
C 2014 Society for Endocrinology Printed in Great Britain 